\title{
METODOLOGIAS ATIVAS E O ENSINO DE EDUCAÇÃO FÍSICA: uma revisão da literatura
}

ACTIVE METHODOLOGY AND PHYSICAL EDUCATION TEACHING: a literature review

METODOLOGÍA ACTIVA Y ENSEÑANZA DE LA EDUCACIÓN FÍSICA: una revisión de la literatura

\author{
Alderise Pereira da Silva Quixabeira \\ Graduada em Educação Física. Mestranda em Ensino em \\ Ciências e Saúde (UFT/Palmas-TO). \\ alderisep@hotmail.com. \\ 0000-0001-7465-2587
}

\section{Anna Rhaquel Araújo Silva}

Cirurgiã-dentista. Especialista em Ortodontia. (CEAOACIEPE).

annaodonto@hotmail.com.

0000-0001-8441-2835

Bárbara Carvalho de Araújo

Graduada em Educação Física. Mestranda em Ensino em Ciências e Saúde (UFT/Palmas-TO).

babicaraujo@gmail.com.

0000-0001-5261-5611

\section{Bruno Costa Silva}

Enfermeiro. Mestrando em Ensino em Ciências e Saúde (UFT/Palmas-TO).

brunocostabc@hotmail.com

0000-0002-7425-7015

\section{Vitor Pachelle Lima Abreu}

Enfermeiro. Mestrando em Ensino em Ciências e Saúde (UFT/Palmas-TO).

vpachelle@gmail.com.

0000-0001-9065-3272

\section{Ana Kleiber Pessoa Borges}

Bióloga, Mestre e Doutora pela UNESP/Rio Claro, SP. Docente na Graduação de Enfermagem na UFT (Universidade Federal do Tocantins, Palmas/TO).

anakleiber@uft.edu.br.

\section{0-0003-1865-2595}

\section{Ruhena Kelber Abrão Ferreira}

Graduado em Educação Física e Doutor em Educação em Ciências e Saúde pela UFRGS e Professor na graduação em Educação Física e Psicologia UFT/Miracema-TO e no Mestrado em Ensino em Ciências e Saúde na UFT/Palmas-TO.

kelberabrao@gmail.com.

0000-0002-5280-6263
Correspondência: Universidade Federal do Tocantins (UFT) | Câmpus de Palmas Quadra 109 Norte, ALCNO14, Avenida NS-15 | Plano Diretor Norte, 77001090 Palmas, TO - Brasil.

Recebido em: 12.10.2020.

Aceito em: 20.11.2020.

Publicado em: 01.01.2021.

\begin{abstract}
RESUMO:
Nesta pesquisa abordamos o uso das Metodologias Ativas no ensino da Educação Física. O objetivo geral é conhecer quais as contribuições das metodologias ativas no desenvolvimento do processo de ensino e aprendizado nas aulas de Educação Física. A pesquisa foi elaborada em uma linha crítica de investigação a abordagem qualitativa. Trata-se de um estudo bibliográfico com as etapas: escolha do tema, levantamento bibliográfico preliminar, análise textual interpretativa e problematização. Encontrase estruturado em subtópicos que discorrem acerca da temática. Ressalta-se que as metodologias ativas baseiam-se em formas de desenvolver o processo de aprender, utilizando experiências reais ou simuladas, visando às condições de solucionar com sucesso, desafios advindos das atividades essenciais da prática social em diferentes contextos, pois, se baseiam em estratégias de ensino fundamentadas na concepção pedagógica crítico e reflexiva que permitem leitura e intervenção sobre a realidade favorecendo a interação entre os diversos atores do processo e valorizando uma construção coletiva do conhecimento e de seus diferentes saberes e cenários de aprendizagem. Além disso, são práticas que estimulam a criatividade na construção de soluções de problemas e promovem a liberdade no processo de pensar e agir.
\end{abstract}

PALAVRAS-CHAVES: Metodologias ativas; Ensino; Aprendizagem; Educação Física.

\section{Introdução}

Com o advento das Novas Tecnologias da Informação e Comunicação, percebemse mudanças abruptas na forma de assimilar e acomodar as informações do mundo 
diário. Paralelo a isso, as novas as exigências profissionais tem contribuído para novas formas de interação entre a sociedade, a escola e o conhecimento. Nesse sentido acreditamos que o sistema educacional no cumprimento de seu principal papel ainda que de forma deficitária, tem permitido o desenvolvimento contínuo dos sujeitos e da sociedade, diante das profundas transformações, que representam desafios múltiplos e diários (Abrão \& Del Pino, 2016).

Ao que se refere a Metodologia Ativa Saviczki ( 2019), relata que a utilização de Metodologias Ativas são alternativas para que se avance na construção de aprendizagens significativas tendo em vista que, pressupõe o protagonismo do estudante, promovendo desta forma, o desenvolvimento de sua autonomia, bem como, de habilidades crítico reflexiva e de resolução de problemas. Por outro lado, indicam que esta prática representa um desafio para os docentes tendo em vista que a maioria deles é oriunda de uma educação tradicional, na qual, o professor ensina e o estudante aprende.

Por outro lado, deve ser levado em consideração o fato de que o trabalho do professor é muito mais do que transmitir conteúdo. É um processo diário que envolve possibilidades variadas e cujo resultado não é perceptível a curto prazo, conforme Triani (2019), à docência é uma profissão ampla que demanda formação pautada nas diferentes possibilidades de atuação, sendo uma prática social condicionada pela singularidade dos contextos nos quais se realiza. A atuação do professor depende diretamente da realidade na qual ele está inserido, seja social, geográfica ou política e que ele deve estar preparado para ajustar a sua prática de acordo com esses fatores.

Tomando como base os contextos históricos da Educação Física no Brasil, conforme Triani (2019), podem ser apontadas algumas relações entre o desenvolvimento dessa área no pais e aspectos políticos de nossa sociedade, refletindo nos propósitos aos quais a disciplina vem se debruçando ao longo de sua existência e com isso no que se refere à forma de participação dos estudantes e da atuação dos professores. A Educação Física só passa ser reconhecida como disciplina com o advento da Lei de Diretrizes e Bases da Educação Nacional Lei 9 394/96 (Brasil, 2013).

Nesta pesquisa abordamos o uso das Metodologias Ativas no ensino da Educação Física, com o objetivo de conhecer quais as contribuições das Metodologias Ativas no desenvolvimento do processo de ensino e aprendizado nessas discutir o ensino por meio das metodologias ativas e as potencialidades dos estudantes, bem como descrever Educação Física no ambiente escolar.

Para nos auxiliar no cumprimento dos objetivos propostos temos como questão que norteia esta investigação: Quais as contribuições da Metodologia Ativa no desenvolvimento do processo de ensino e aprendizado nas aulas de Educação Física? 
Nesse sentido, temos como aliado no processo de desenvolvimento de ensino e aprendizado do estudante por meio das metodologias ativas.

\section{Metodologia}

Esta pesquisa possui delineamento bibliográfico que para Marconi e Lakatos (2003), "abrange toda bibliografia já tornada pública em relação ao tema estudado, desde publicações avulsas, boletins, jornais, revistas, livros, pesquisas, monografias, teses, materiais cartográficos, etc. [...] e sua finalidade é colocar o pesquisador em contato direto com tudo o que foi escrito, dito ou filmado sobre determinado assunto".

Para a realização da revisão de literatura que originou este trabalho foram utilizadas as palavras-chave "Metodologias Ativas"; "Ensino" e "Educação Física", na base de dados da Biblioteca Digital Brasileira de Teses e Dissertações (BDTD) no idioma português. Foram utilizados os seguintes critérios: idioma português; período de busca: entre os anos de 2010 a 2020: apenas artigos originais e artigos de revisão, referente ao tipo de documento; e temática proposta.

Objetivando aprimorar a revisão foram estabelecidos critérios de exclusão: Relatos de experiências; Tome Ciência (Publica resumos de monografias concluídas em cursos de graduação e pós-graduação lato sensu). A face do objetivo proposto fora analisada elementos que perpetram o conceito de Metodologia Ativa; Ensino e Educação Física, abrangendo suas concepções e significados presentes na literatura.

Logo abaixo, no quadro 1 apresentamos a quantidade de dissertações e teses encontradas, conforme cada palavra-chave utilizada na busca, aplicando os critérios e filtros determinados. Esta busca foi realizada no período de 05 a 12 de junho de 2020 . Vale ressaltar que a base de dados recebe e torna públicos os trabalhos de diversas instituições formadoras, fato este que eleva o quantitativo de publicações. Desta forma, novas publicações disponibilizadas nas bases de dados pesquisadas após esse período foram desconsideradas.

Quadro 1 Levantamento de dissertações na base de dados

\begin{tabular}{|l|l|l|l|}
\multicolumn{1}{|c|}{ Palavra-chave } & \multicolumn{1}{|c|}{$\begin{array}{c}\text { Dissertações } \\
\text { encontradas }\end{array}$} & $\begin{array}{c}\text { Dissertações } \\
\text { excluídas }\end{array}$ & $\begin{array}{c}\text { Dissertações } \\
\text { selecionadas }\end{array}$ \\
\hline Metodologia Ativa & 15.218 & 15.214 & 03 \\
\hline Ensino & 46.175 & 46.172 & 03 \\
\hline Educação Física & 7.165 & 7.162 & 03 \\
\hline Total & 68.558 & 68.548 & 09 \\
\hline
\end{tabular}

Fonte: Elaboração dos autores, 2020.

Quadro 2 Levantamento de teses na base de dados 


\begin{tabular}{|l|l|l|l|}
\multicolumn{1}{|c|}{ Palavra-chave } & \multicolumn{1}{c|}{ Teses encontradas } & \multicolumn{1}{c|}{ Teses excluídas } & Teses selecionadas \\
\hline Metodologias Ativas & 5.501 & 5.498 & 03 \\
\hline Ensino & 12.875 & 12.872 & 03 \\
\hline Educação Física & 1.957 & 1.954 & 03 \\
\hline Total & $\mathbf{2 0 . 3 3 3}$ & $\mathbf{2 0 . 3 2 4}$ & 09 \\
\hline
\end{tabular}

Fonte: Elaboração dos autores, 2020.

Quadro 3 Levantamento de dissertações utilizadas

\begin{tabular}{|c|c|c|c|c|}
\hline Palavras-chave & Autor (a) & Titulo & Instituição & Ano \\
\hline \multirow{3}{*}{$\begin{array}{l}\text { Metodologia } \\
\text { Ativa }\end{array}$} & $\begin{array}{l}\text { ALVES, } \quad \text { Amanda } \\
\text { Gouveia. }\end{array}$ & $\begin{array}{l}\text { Mágicas matemáticas } \\
\text { como metodologia de } \\
\text { ensino. }\end{array}$ & $\begin{array}{l}\text { Universidade } \\
\text { Federal de São } \\
\text { Carlos }\end{array}$ & 2015 \\
\hline & $\begin{array}{l}\text { SAVICZKI, } \\
\text { Caroline }\end{array}$ & $\begin{array}{l}\text { Prática pedagógica de } \\
\text { professores em cursos } \\
\text { técnicos de nível médio: } \\
\text { Aplicação de } \\
\text { Metodologias Ativas. }\end{array}$ & $\begin{array}{l}\text { Escola de } \\
\text { Humanidades } \\
\text { da Pontifícia } \\
\text { Universidade } \\
\text { Católica do Rio } \\
\text { Grande do Sul. }\end{array}$ & 2019 \\
\hline & $\begin{array}{l}\text { SILVA, Claudinei } \\
\text { Gonçalves da. }\end{array}$ & 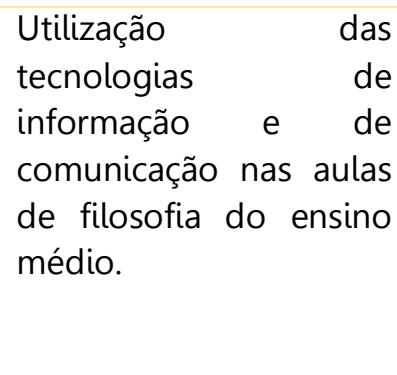 & $\begin{array}{l}\text { Centro de } \\
\text { Ensino } \\
\text { Pesquisa } \\
\text { Aplicada à } \\
\text { Educação da } \\
\text { Universidade } \\
\text { Federal de } \\
\text { Goiás. }\end{array}$ & 2019 \\
\hline \multirow[t]{3}{*}{ Ensino } & $\begin{array}{l}\text { OLIVEIRA, Victor José } \\
\text { Machado. }\end{array}$ & $\begin{array}{l}\begin{array}{l}\text { Saúde na educação } \\
\text { física }\end{array} \\
\text { ambivalar: } \\
\text { pedagógicas. e práticas }\end{array}$ & $\begin{array}{l}\text { Universidade } \\
\text { Federal do } \\
\text { Espírito Santo. }\end{array}$ & 2014 \\
\hline & $\begin{array}{l}\text { NUNES, Tayna } \\
\text { Cristine Fontenele. }\end{array}$ & $\begin{array}{l}\text { Metodologias de Ensino } \\
\text { em cursos de } \\
\text { licenciatura em } \\
\text { educação física: Uma } \\
\text { discussão necessária. }\end{array}$ & $\begin{array}{l}\text { Universidade } \\
\text { Estadual do } \\
\text { Ceará. }\end{array}$ & 2018 \\
\hline & $\begin{array}{l}\text { MARTINS, Poliana } \\
\text { Carvalho. }\end{array}$ & $\begin{array}{lll}\text { A organização } & \text { da } \\
\text { educação física } & \text { na } \\
\text { educação infantil } & \text { no } \\
\text { DEI/CEPAE/UFG. } & \end{array}$ & $\begin{array}{l}\text { Universidade } \\
\text { Federal de } \\
\text { Goiás }\end{array}$ & 2019 \\
\hline $\begin{array}{l}\text { Educação } \\
\text { Física }\end{array}$ & GIANOLLA, Fábio. & $\begin{array}{l}\text { A percepção dos alunos } \\
\text { e professores de uma } \\
\text { faculdade de educação } \\
\text { física com relação ao } \\
\text { papel do profissional de } \\
\text { educação física na área } \\
\text { da saúde. }\end{array}$ & $\begin{array}{l}\text { Pontifica } \\
\text { Universidade } \\
\text { Católica de São } \\
\text { Paulo. }\end{array}$ & 2016 \\
\hline
\end{tabular}




\begin{tabular}{|c|c|c|}
\hline $\begin{array}{l}\text { FERNANDES, } \\
\text { Kessiane Brito. }\end{array}$ & $\begin{array}{l}\text { Atividade física e saúde } \\
\text { na educação física } \\
\text { escolar: perspectiva de } \\
\text { docentes do ensino } \\
\text { superior. }\end{array}$ & $\begin{array}{l}\text { Universidade } \\
\text { Estadual do } \\
\text { Ceará. }\end{array}$ \\
\hline $\begin{array}{l}\text { SOUZA, } \\
\text { Lanes. }\end{array}$ & $\begin{array}{l}\text { Educação física na área } \\
\text { das linguagens. }\end{array}$ & $\begin{array}{l}\text { Universidade } \\
\text { Federal de } \\
\text { Santa Maria }\end{array}$ \\
\hline
\end{tabular}

Total

Fonte: Elaboração dos autores, 2020.

Quadro 4 Levantamento de teses utilizadas

\begin{tabular}{|c|c|c|c|c|}
\hline Palavras-chave & Autor (a) & Titulo & Instituição & Ano \\
\hline \multirow[t]{3}{*}{$\begin{array}{l}\text { Metodologias } \\
\text { Ativas }\end{array}$} & $\begin{array}{l}\text { MONTENEGRO, } \\
\text { Gustavo Maneschy. }\end{array}$ & 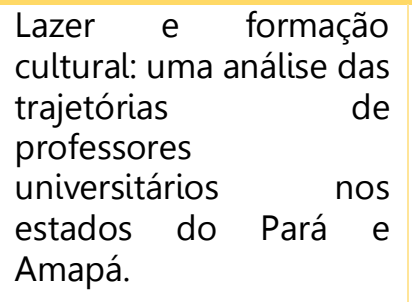 & $\begin{array}{l}\text { Universidade } \\
\text { Federal de } \\
\text { Minas Gerais. }\end{array}$ & 2019 \\
\hline & $\begin{array}{l}\text { TRIANI, } \quad \text { André } \\
\text { Pereira. }\end{array}$ & $\begin{array}{l}\text { Condições de trabalho e } \\
\text { atuação docente dois- } \\
\text { pontos a realidade dos } \\
\text { professores de } \\
\text { educação física de Boa } \\
\text { Vista - RR }\end{array}$ & $\begin{array}{l}\text { Universidade } \\
\text { Federal de Juiz } \\
\text { de Fora. }\end{array}$ & 2019 \\
\hline & $\begin{array}{l}\text { VENTURA, Paula } \\
\text { Patrícia Barbosa. }\end{array}$ & $\begin{array}{l}\text { Indicadores de } \\
\text { Metodologias Ativas } \\
\text { com suporte das } \\
\text { tecnologias digitais: } \\
\text { estudo com docentes do } \\
\text { Instituto Federal de } \\
\text { Educação, Ciência e } \\
\text { Tecnologia do Ceará. }\end{array}$ & $\begin{array}{l}\text { Universidade } \\
\text { Estadual do } \\
\text { Ceará. }\end{array}$ & 2019 \\
\hline \multirow[t]{3}{*}{ Ensino } & $\begin{array}{l}\text { BASTOS, Robson dos } \\
\text { Santos. }\end{array}$ & $\begin{array}{l}\text { A educação para a } \\
\text { cidadania global da } \\
\text { UNESCO e seus nexos } \\
\text { com a formação de } \\
\text { professores } \\
\text { Educação Física no Pará. }\end{array}$ & $\begin{array}{l}\text { Universidade } \\
\text { Federal do Pará } \\
\text { - UFPA. }\end{array}$ & 2019 \\
\hline & $\begin{array}{l}\text { METZNER, Andreia } \\
\text { Cristina }\end{array}$ & $\begin{array}{l}\text { Legislação sobre a } \\
\text { formação em Educação } \\
\text { Física no Brasil: } \\
\text { formando professores } \\
\text { ou profissionais? }\end{array}$ & $\begin{array}{l}\text { Universidade } \\
\text { Estadual } \\
\text { Paulista } \\
\text { (Unesp). }\end{array}$ & 2019 \\
\hline & $\begin{array}{l}\text { MIRANDA, Cristiano } \\
\text { José Martins de. }\end{array}$ & $\begin{array}{l}\text { O Processo de } \\
\text { Aprendizagem } \\
\text { Significativa } \\
\text { Conceitos em Aulas de }\end{array}$ & $\begin{array}{l}\text { Instituto } \\
\text { Oswaldo Cruz } \\
\text { do Rio de } \\
\text { Janeiro. }\end{array}$ & 2019 \\
\hline
\end{tabular}




\begin{tabular}{|c|c|c|c|c|}
\hline & & $\begin{array}{l}\text { Educação Física do } \\
\text { Ensino Médio }\end{array}$ & & \\
\hline \multirow[t]{3}{*}{$\begin{array}{l}\text { Educação } \\
\text { Física }\end{array}$} & $\begin{array}{l}\text { GOMES, Luciane de } \\
\text { Almeida. }\end{array}$ & $\begin{array}{ll}\text { Eu, o professor: } & \text { um } \\
\text { estudo sobre } & \\
\text { desenvolvimento } & \\
\text { profissional de } & \\
\text { professores } & \text { de } \\
\text { educação física } & \text { em } \\
\text { início de } & \\
\text { carreira. } & \end{array}$ & $\begin{array}{l}\text { Universidade } \\
\text { Federal de } \\
\text { Mato } \\
\text { Grosso, } \\
\text { Instituto de } \\
\text { Educação. }\end{array}$ & 2019 \\
\hline & $\begin{array}{l}\text { OLIVEIRA, Sandra } \\
\text { Regina Garijo de. }\end{array}$ & $\begin{array}{l}\text { A Educação Física e a } \\
\text { Inclusão de pessoas com } \\
\text { deficiência na escola: } \\
\text { Umararara } \\
\text { sistemática-integrativa. }\end{array}$ & $\begin{array}{l}\text { Pontifica } \\
\text { Universidade } \\
\text { Católica de São } \\
\text { Paulo. }\end{array}$ & 2019 \\
\hline & SOUZA, Joel Silva de & $\begin{array}{l}\text { Memória muscular: um } \\
\text { estudo interdisciplinar } \\
\text { sobre a performance no } \\
\text { violoncelo. }\end{array}$ & $\begin{array}{l}\text { Universidade } \\
\text { Estadual } \\
\text { Paulista "Julio } \\
\text { de Mesquita } \\
\text { Filho", Instituto } \\
\text { de Artes. }\end{array}$ & 2020 \\
\hline
\end{tabular}

Fonte: Elaboração dos autores, 2020.

\section{Resultados e Discussões}

Ao que se refere à pesquisa, iniciamos por destacar que tanto as dissertações quanto as teses encontradas, estão completas, disponíveis no formato online, escritas em língua portuguesa e são de instituições de formação diversas. Desse modo, ao realizarmos a busca por dissertações, ao utilizarmos a palavra-chave Metodologias Ativas, foram encontradas 15.218, dissertações, dessas foram excluídas 15.215, sendo que 03 compuseram os dados desse trabalho. Enquanto a palavra ensino foram encontradas 46.175 dissertações dessas foram excluídas 46.172, sendo que 03 compuseram os dados desse trabalho. Já ao que diz respeito a pesquisa realizada tendo como palavra-chave educação física foram encontradas 7.165 dissertações, desse quantitativo foram excluídas 7.162, ficando 03 para composição deste trabalho. Assim, no total encontramos 68.558, excluímos 68.549, e usamos 09 como base teórica para compor os dados desse trabalho, conforme apresenta o (quadro 1).

Na realização da pesquisa em busca de teses, foram encontradas 5.501, todas disponíveis no formato online, escritas em língua portuguesa e de diversas instituições. Tendo como palavra-chave Metodologias Ativas foram encontradas 5.501, dessas foram excluídas 5.498, sendo selecionadas 03. Usando a palavra-chave Ensino encontramos 12.875, destas foram excluídas 12.872, ficando para compor os dados desse trabalho 03 
teses. Já com a palavra Educação Física foram encontradas 1.957, desse total foram excluídas 1.954, e 03 compuseram os dados desse trabalho, ao realizarmos a pesquisa obtivemos um total de 20.333 teses, desse quantitativo 20.324 foram excluídos, e 09 compuseram os dados desse trabalho, de acordo evidenciado no (quadro 02).

Os dados permitem destacar a representatividade do Brasil na produção científica sobre: Metodologias Ativas; Ensino; e Educação Física, disponível na base de dados do repositório, acessado por meio do link: <http://bdtd.ibict.br/vufind/Search/Advanced>.

O quadro 03 exibe o levantamento de dissertações utilizadas, apresenta, o nome do autor, o título da dissertação, instituição e ano, nesse quadro ficou evidenciado, que 01 dissertação foi publicada no ano de 2014; 01 com publicação em 2015; 01 no ano de 2016; 01 no ano de 2017; 02 no ano de 2018 e 03 com publicação em 2019, totalizando assim, 09 dissertações analisadas, porém das analisadas nem todas foram citadas no macro teórico deste trabalho.

Já no quadro 04 apresentamos o levantamento das teses que compuseram os dados desse artigo, assim como o quadro das dissertações, o das teses, também, apresenta o nome do autor, o título da dissertação, instituição e ano, ficou que das 09 teses selecionadas, somente 01 foi publicada no ano de 2020 , as outras 08 são todas referentes ao ano de 2019. Das 09 apresentadas nem todas foram citadas no macro teórico desse trabalho, todavia, serviram como embasamento. Para tanto, foram selecionados entre dissertações e teses 11 trabalhos que compuseram as informações postas neste trabalho, porém não aparecem todos citados no marco teórico.

\section{Marco Teórico}

Apresentamos aqui uma revisão da literatura com a intenção de dar suporte teórico às ações desenvolvidas ao longo da pesquisa. Inicialmente, abordamos os aspectos históricos e conceituais da atividade física, na qual buscamos ampliar o entendimento de Metodologias Ativas, no desenvolvimento do processo de ensino e aprendizado nas aulas de Educação Física; e discutimos a inovação no contexto de sala de aula; discorremos acerca do processo de ensino e aprendizado nas aulas de educação física.

No subtópico seguinte debatemos sobre ensino por meio das Metodologias Ativas e as potencialidades dos estudantes nas aulas de Educação Física buscando assim ampliar o entendimento acerca da temática e, por último, descrevemos sobre o ensino por meio das Metodologias Ativas e as potencialidades dos estudantes nas aulas de Educação Física. 
Metodologias Ativas: Desenvolvimento no processo de ensino e aprendizado nas aulas de Educação Física

Ao ampliar o entendimento de Metodologias Ativas, no desenvolvimento do processo de ensino e aprendizado nas aulas de Educação Física, com base na literatura de Ventura ( 2019), seis indicadores de Metodologias Ativas foram propostos: Valorização da Autonomia, Valorização das Produções Intelectuais; Engajamento Ativo no Processo de Aprendizagem, Estímulo à Participação do Discente; Pesquisa como Princípio Educativo e Equilíbrio entre Atividades Individuais e Coletivas.

Para Saviczki (2019), as Metodologias Ativas diante dos indicadores citados por Ventura são pontos de partida para prosseguir para processos mais avançados de reflexão e integração cognitiva, de generalização, de reelaboração de novas práticas.

Saviczki (2019) conclui que:

\begin{abstract}
Metodologia Ativa é um processo de ensinagem dialógico, aberto, ativo e participativo que, por meio da curiosidade, da problematização, da relação teoria/prática, da significação, da correlação, da elaboração da síntese do conhecimento, objetiva a resoluções de problemas e situações, a construção do conhecimento e de autonomia e a formação da cidadania, na qual o estudante autogerencia seu aprendizado tendo o docente como instigador e mediador. (Saviczki, 2019.).
\end{abstract}

Saviczki (2019) acrescenta que a inovação no contexto de sala de aula se apresenta como uma necessidade em todas as modalidades de ensino. Diante da velocidade, com que avançam as tecnologias e da disponibilidade de informação, é imperativo a utilização de Metodologias Ativas que aproximem os estudantes da realidade do mercado de trabalho e da vida em sociedade e que permitam o desenvolvimento de aprendizagens contextualizadas, com as exigências de um mundo sem fronteiras, interconectado e cada vez mais complexo.

Nessa perspectiva Ventura (2019), pondera que nas Metodologias Ativas, o professor deve participar assiduamente de todo o processo e não se esquivar ou ausentar-se quando é exigido o desenvolvimento de atividades ou a responsabilidade maior é delegada ao aluno. Tal fato requer um trabalho docente assíduo, de acompanhamento, supervisão, retorno, olhar e escuta sensível aos êxitos e dificuldades dos discentes.

De acordo, Saviczki (2019), as Metodologias Ativas são alternativas para tornar o processo de aprendizagem mais atrativo e motivador, à medida que incentiva o potencial criativo dos estudantes, proporciona a geração de ideias, de diversas possiblidades de 
respostas para antigas ou novas questões, reconhece no erro oportunidades para novas construções.

Segundo Saviczki (2019), discutir Metodologia Ativa tomando-a como centro das discussões revela o questionamento, em que se colocam as formas tradicionais de ensino e aprendizagem, centradas na transmissão/assimilação e reduzidas à memorização.

Para tanto Saviczki (2019), delineia que nesse mundo da informação globalizada, do conhecimento acessível e da reconfiguração das competências profissionais, é fundamental encontrar meios para superar as passividades dos aprendentes, em relação à construção de suas aprendizagens, criando estratégias nas quais eles se tornem investigadores ativos do contexto, no qual estão inseridos, possibilitando a reflexão sobre os conhecimentos já adquiridos e ressignificando seus saberes, superando, assim, a visão dualista da teoria e da prática. Nesse sentido, é importante que professores lancem mão de Metodologias Ativas, capazes de tornar os estudantes protagonistas do seu processo de aprendizagem.

Desse modo, é possível entender que as Metodologias Ativas baseiam-se em formas de desenvolver o processo de aprender, utilizando experiências reais ou simuladas, visando às condições de solucionar, com sucesso, desafios advindos das atividades essenciais da prática social, em diferentes contextos (Saviczki, 2019).

\section{Ensino por meio das Metodologias Ativas e as potencialidades dos estudantes nas aulas de Educação Física}

Em seus estudos Nunes (2018) assegura que o uso das Metodologias Ativas passa a ser uma alternativa, nas aulas de Educação Física, pois se baseiam em estratégias de ensino fundamentadas na concepção pedagógica crítico e reflexiva que permitem leitura e intervenção sobre a realidade, favorecendo a interação entre os diversos atores do processo e valorizando uma construção coletiva do conhecimento e de seus diferentes saberes e cenários de aprendizagem. Além disso, são práticas que estimulam a criatividade na construção de soluções de problemas e promovem a liberdade no processo de pensar e agir.

Dessa forma Martins (2019) discorre que a relação do estudante com o professor de Educação Física, articulada pela atividade de ensino por meio das Metodologias Ativas e estabelecida com o engajamento de ambos proporciona, efetivamente, uma segunda natureza aos estudantes. Um exemplo desse aprendizado e desenvolvimento pode ser o alcance e o controle que o estudante passa a ter de seu comportamento após um longo processo de ensino por parte do professor ou de outro mais experiente. Diante dessa constatação, é necessário saber como o estudante aprende e se desenvolve para 
organizar o ensino de forma a torná-lo mais apropriado às crianças e a potencializar seu desenvolvimento.

Semelhantemente, Nunes (2018), descreve que ao trabalhar a Metodologia Ativa o papel do estudante é ativo, o foco é desviado para que seja responsável pelo seu próprio ensino. Passa a exercer atitude crítica e construtiva se bem orientado. Uma das vantagens de se desenvolver essa metodologia nas aulas de Educação Física é a possibilidade de individualizar as necessidades dos estudantes, facilitando a interação aluno-professor. A desvantagem é que consome enorme tempo docente de preparo, aplicação e avaliação da atividade. Requer o trabalho com pequenos grupos para que seja efetiva, requer o sacrifício de se transmitir todo o conteúdo, sendo necessário selecionar o conteúdo essencial.

Nesse sentido, Bastos (2019), afirma que ao se trabalhar nas aulas de Educação Física a partir das Metodologias Ativas, corresponde ao aprender a adaptar-se às necessidades do modo de produção vigente, cabendo a educação escolar promover os instrumentos necessários para esse fim que, de modo geral, está associado ao ensino de conhecimentos atitudinais, de valores comportamentais e competências e habilidades para que o estudante possa se adaptar ao atual modo de produção e desenvolvimento no processo de ensino e aprendizado.

Miranda (2019) analisa que ensinar à luz da Metodologia Ativa é favorecer a aprendizagem, isto é, ensinar compreende um conjunto de ações que o professor (considerando a natureza do conhecimento, do contexto e do perfil dos próprios estudantes) realiza para ajudar o estudante a aprender significativamente um determinado tema. Para tanto, neste contexto, o compartilhar significados resulta da negociação de significados entre estudante e professor, as essas negociações devem envolver uma permanente troca de perguntas ao invés de respostas.

Acrescenta ainda que uma situação de ensino se efetiva quando estudantes e professores compartilham significados do material de ensino. Esta tríade, por sua vez, caracteriza um contexto único, particular, permitindo que em cada aula, ou mesmo no contexto de uma aula, possamos ter várias situações de ensino. Assim, cada encontro, seja uma aula ou ano letivo é singular, impossível de ser reproduzido, mesmo que os sujeitos e cenários sejam os mesmos.

\section{Educação Física no ambiente escolar}

No final do século XIX e partir do século XX, a Educação Física no Brasil esteve intensamente vinculada às instituições médicas e militares. Estas orientaram o caminho desta disciplina escolar, delineando o seu espaço e delimitando seu campo de 
conhecimento, tornando-a um instrumento de ação e intervenção na realidade educacional e social (Fernandes, 2017).

A autora acrescenta ainda que a inserção da saúde na ambiência escolar se deu por via do discurso higienista, sendo atribuída à Faculdade de Medicina do Rio de Janeiro a tarefa de instruir professores dos cursos primários e da Escola Normal sobre noções de higiene. Para a obtenção deste objetivo, a intervenção escolar sucedia com base em três doutrinas: a polícia médica, pela inspeção das condições de saúde; o sanitarismo, pelo cuidado com o ambiente de ensino; e a puericultura, pela divulgação de regras relacionadas a como viver (Fernandes, 2017).

A obrigatoriedade da prática da Educação Física conforme Metzner (2019), até os 18 anos tinha como premissa a capacitação física dos estudantes com o intuito de formar o futuro trabalhador. A autora complementa que a própria limitação com relação aos 18 anos de idade indica que essa prática deveria ser interrompida para não causar desgaste ou exaustão em um momento em que os indivíduos necessitam de maior energia e disposição para o ingresso no mercado de trabalho.

Logo Fernandes (2019), delineia que a Educação Física escolar deve propiciar o conhecimento sobre as atividades físicas voltadas para o bem-estar e saúde, estimular atitudes positivas em relação aos exercícios físicos; ensejar distintas práticas de maneira regular para que possam ser continuadas após o desligamento da escola e promover liberdade na escolha das atividades físicas relacionadas à saúde.

Nesse sentido, Metzner (2019), escreve que a trajetória histórica da formação em Educação Física mostra que a legislação marcou, e ainda marca, a sua constituição enquanto profissão. No Brasil, a Educação Física foi construída por meio de embates políticos, epistemológicos e ideológicos.

Somente em 1996, a nova Lei de Diretrizes e Bases da Educação Nacional Lei 9.394 de 20 de dezembro de 1996, (Brasil, 2013), que posicionou a Educação Física no mesmo patamar das demais disciplinas, considerando-a como componente curricular da Educação Básica.

Desta maneira, Metzner (2019), adiciona que a Educação Física ao ser instituída, por meio de uma legislação nacional, uma das disciplinas que compõem a estrutura curricular da Educação Básica, fez com que se acentuasse a preocupação de integrá-la à proposta pedagógica da escola

\section{Considerações Finais}

No que tange as Metodologias Ativas e o desenvolvimento no processo de ensino e aprendizado nas aulas de Educação Física, ficou evidente que essa abordagem 
pedagógica são alternativas para tornar o processo de aprendizagem mais atrativo e motivador. Acredita-se que isso acontece à medida que incentiva o potencial criativo dos estudantes, proporciona a geração de ideias, de diversas possiblidades de respostas para antigas ou novas questões e reconhecer no erro, se houver, oportunidades para novas construções.

Ao discutirmos sobre ensino por meio das Metodologias Ativas e as potencialidades dos estudantes nas aulas de Educação Física ficou evidenciado que a relação do estudante com o professor de Educação Física articulada pela atividade de ensino por meio das Metodologias Ativas e estabelecida com o engajamento de ambos proporciona, efetivamente, uma segunda natureza aos estudantes. Um exemplo desse aprendizado e desenvolvimento pode ser o alcance e o controle que o estudante passa a ter de seu comportamento após um longo processo de ensino por parte do professor ou de outro mais experiente.

Em relação Educação Física no ambiente escolar, ficou ilustrado que esta deve propiciar o conhecimento sobre as atividades físicas voltadas para o bem-estar e saúde, estimular atitudes positivas em relação aos exercícios físicos; ensinar distintas práticas de forma regular para que possam ser continuadas após o desligamento da escola e promover liberdade na escolha das atividades físicas relacionadas à saúde.

Por fim, podemos inferir que Metodologias Ativas são estratégias que requerem e incentivam a participação intensa e permanente do aluno, ampliando assim a atenção aos interesses múltiplos, diante da diversidade de caminhos que se apresentam possíveis; estimulam a liberdade de escolha; priorizam a aplicação do conhecimento construído, a partir de experiências dos alunos; valorizam atividades realizadas em grupos e o compartilhamento dos resultados alcançados; consideram diferentes formas de utilização de recursos empíricos, científicos, culturais, sociais e tecnológicos a serem mobilizados, para que se construam aprendizagens significativas e para que se desenvolvam competências. Existem poucas pesquisas acerca das metodologias ativas no ensino e aprendizado nos cursos de Educação Física, necessitando maior incentivo na produção destas.

\section{Referências}

Abrão, K. R., \& Del Pino, J. C. (2016). Cognição e aprendizagem no espaço da tecnologia. Revista Ibero-Americana de Estudos Em Educação, 11(4), 1776-1798. https://doi.org/10.21723/riaee.v11.n4.5934

Bastos, R. dos S. (2019). A EDUCAÇÃO PARA A CIDADANIA GLOBAL DA UNESCO E SEUS NEXOS COM A FORMAÇÃO DE PROFESSORES DE EDUCAÇÃO FÍSICA NO PARÁ [Universidade federal do Pará]. https://scholar.google.com.br/scholar?hl=pt- 
BR\&as_sdt $=0 \% 2 C 5 \& q=A+$ educação + para $+a+$ cidadania + global + da $+U N E S C O+e$ + seus + nexos+com +a+formação + de+professores + de+educação+física +no+Par á\&btnG =

Brasil. (2013). Diretrizes Curriculares Nacionais Gerais da Educação Básica.

Fernandes, K. B. (2017). ATIVIDADE FÍSICA E SAÚDE NA EDUCAÇÃO FÍSICA ESCOLAR: PERSPECTIVA DE DOCENTES DO ENSINO SUPERIOR.

Marconi, M., \& Lakatos, E. (2003). Fundamentos de metodologia científica. In Editora Atlas S. A. https://doi.org/10.1590/S1517-97022003000100005

Martins, P. C. (2019). A ORGANIZAÇÃO DA EDUCAÇÃO FÍSICA NA EDUCAÇÃO INFANTIL NO DEI/CEPAE/UFG. https://repositorio.bc.ufg.br/tede/handle/tede/10128

Metzner, A. C. (2019). Legislação sobre a formação em Educação Física no Brasil: formando professores ou profissionais? [Universidade Estadual Paulista (Unesp)]. https://repositorio.unesp.br/handle/11449/191044

Miranda, C. J. M. de. (2019). O PROCESSO DE APRENDIZAGEM SIGNIFICATIVA DE CONCEITOS EM AULAS DE EDUCAÇÃO FÍSICA DO ENSINO MÉDIO [Instituto Oswaldo Cruz]. https://www.arca.fiocruz.br/handle/icict/39523

Nunes, T. C. F. (2018). METODOLOGIAS DE ENSINO EM CURSOS DE LICENCIATURA EM EDUCAÇÃO FÍSICA: UMA DISCUSSÃO NECESSÁRIA [Universidade Estadual do Ceará (UECE)]. https://doi.org/10.1017/CBO9781107415324.004

Saviczki, S. C. (2019). PRÁTICA PEDAGÓGICA DE PROFESSORES EM CURSOS TÉCNICOS DE NÍVEL MÉDIO: APLICAÇÃO DE METODOLOGIAS ATIVAS [Escola de Humanidades]. http://tede2.pucrs.br/tede2/handle/tede/8589

TRIANI, A. P. (2019). CONDIÇÕES DE TRABALHO E ATUAÇÃO DOCENTE: A REALIDADE DOS PROFESSORES DE EDUCAÇÃO FÍSICA DE BOA VISTA - RR [Universidade Federal de Juiz de Fora]. http://www.ufjf.br/ppge/files/2019/03/TESE-ANDRÉTRIANI.pdf

Ventura, P. P. B. (2019). Indicadores de metodologias ativas com suporte das tecnologias digitais: estudo com docentes do Instituto Federal de Educação, Ciência e Tecnologia do Ceará [Universidade Federal do Ceará-UFC]. http://www.repositorio.ufc.br/bitstream/riufc/40528/3/2019_tese_ppbventura.pdf 


\section{Cevisto Observatório}

e-ISSN n² 2447-4266

rg/10.20873/uft.2447-4266.2021v7n1a12pt

\begin{abstract}
:
In this research we approach the use of Active Methodologies in the teaching of Physical Education. The general objective is to know the contributions of the active methodologies in the development of the teaching and learning process in Physical Education classes. The research was elaborated in a critical line of investigation using the qualitative approach. This is a bibliographic study with the steps: choice of theme, preliminary bibliographic survey, interpretative textual analysis and problematization. It is structured in subtopics that discuss the theme. It is noteworthy that the active methodologies are based on ways of developing the learning process, using real or simulated experiences, aiming at the conditions to successfully solve challenges arising from the essential activities of social practice in different contexts, because they are based on teaching strategies based on a critical and reflective pedagogical conception that allow reading and intervention on reality, favoring the interaction between the different actors of the process and valuing a collective construction of knowledge and its different knowledge and learning scenarios. In addition, they are practices that stimulate creativity in building problem solutions and promote freedom in the process of thinking and acting.
\end{abstract}

KEYWORDS: Active methodologies; Teaching; Learning; PE.

\section{RESUMEN:}

En esta investigación abordamos el uso de metodologías activas en la enseñanza de la educación física. El objetivo general es conocer las contribuciones de las metodologías activas en el desarrollo del proceso de enseñanza y aprendizaje en las clases de Educación Física. La investigación se elaboró en una línea crítica de investigación utilizando el enfoque cualitativo. Este es un estudio bibliográfico con los pasos: elección del tema, encuesta bibliográfica preliminar, análisis textual interpretativo y problematización. Está estructurado en subtemas que discuten el tema. Es de destacar que las metodologías activas se basan en formas de desarrollar el proceso de aprendizaje, utilizando experiencias reales o simuladas, apuntando a las condiciones para resolver con éxito los desafíos que surgen de las actividades esenciales de la práctica social en diferentes contextos, porque se basan en Estrategias de enseñanza basadas en una concepción pedagógica crítica y reflexiva que permita la lectura y la intervención sobre la realidad, favoreciendo la interacción entre los diferentes actores del proceso y valorando una construcción colectiva del conocimiento y sus diferentes escenarios de conocimiento y aprendizaje. Además, son prácticas que estimulan la creatividad en la construcción de soluciones a problemas y promueven la libertad en el proceso de pensar y actuar.

PALABRAS-CLAVES: Metodologías activas; Enseñando; Aprendizaje; Educación Física. 